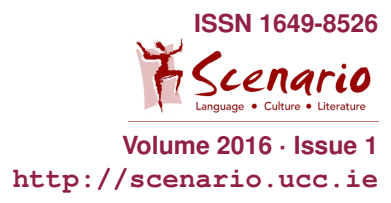

Window of Practice

\title{
Performative Script analysis for additional language classrooms
}

\author{
Robin Reid
}

\begin{abstract}
Theatre offers a wide variety of activity that can be adapted for the language learning classroom. In recent decades, the primary focus of such activity has been improvisation and related techniques and games, with practices more specifically connected with conventional script-based theatre (and other forms of scripted role-play) receiving less attention. Building on top of several years of classroom experimentation, this paper describes a set of procedures for a script-based classroom activity that modifies the basic rehearsal practice of script analysis into a more deliberately sequenced series of tasks. This task sequence makes basic character and scene analysis more accessible to students without any theatre or other performing arts experience, and offers those students a collaborative, problemsolving task that is challenging and enjoyable. Student feedback from an exploration of this task indicates the intrinsic motivation that it provides and the opportunities it affords for language development.
\end{abstract}

\section{Introduction}

This paper discusses a variation of theatrical rehearsal practice that I adapted for a university level English for Academic Purposes (EAP) English course on which I taught and is also based, in part, on a workshop presentation I gave at the 2013 WATESOL conference in Wellington, New Zealand. The activity and its procedures, which are described in this paper, originated in my experiences and training as an undergraduate in theatre studies and also draws from my subsequent career in the performing arts. While the practice of script analysis is definitely not a new invention, being, as it is, one of the most fundamental activities that modern actors undertake in preparing for rehearsal, I feel this particular procedural variation of the practice is novel for second or additional (L2) language classrooms. I had wanted to experiment with scripted performance in my classrooms for some time, so I designed this activity to be feasible for students without any experience with the performing arts.This paper is arranged as follows: Firstly, I provide a brief background and rationale 
for the activity. Next, I explain in detail the procedures of the task. Lastly, I will briefly discuss students' post-task feedback collected from an exploratory study in which students undertook two iterations of the script analysis task. I conclude this paper with a brief discussion of the findings of this study and offer some suggestions for future implementation.

\section{Theatre and drama in L2 learning}

While theatre in its unaltered form (i.e. a full-scale production such as the one described in Smith, 1984) is still quite rare in L2 contexts, numerous teachers throughout the L2 teaching field make use of activities that either mirror or draw inspiration from theatre practice without necessarily endeavouring to undertake a conventional theatrical process. Such activities are typically various skits and improvisation games like those found in the lesson manuals of Maley \& Duff (1978) and Wessels (1987), for example. Coupled with this theatrical activity are role-play variants without artistic underpinnings or public exhibition, such as scenarios (Di Pietro, 1987) and simulations (Jones, 1982) and on top of these there has been an emergence in recent decades of 'drama'-based variants, such as process drama (e.g. Kao \& O’Neill, 1998; Piazzoli 2010, 2011), which are centred around dramatic situations sustained through improvisational role-play and have been conceptualised as pedagogical approaches in their own right in both L1 and L2 contexts. As the wide variety of applications indicates, the past few decades has seen an increase in studies devoted to theatre and drama across subject areas (e.g. see Belliveau \& Kim, 2013 for a review of studies in L2 contexts, and either Podlozny, 2000 or Mages, 2008 for L1 contexts) and there has been a particular emerging interest in utilising drama for English L2 learning in many East Asian contexts (e.g. Donnery, 2009; Stinson \& Winston, 2011). The wide variety of forms that imaginative role-play has assumed in educational contexts all share a similar range of purported benefits, including language skills development, improvement of interpersonal communication and empathetic ability, sociological and psychological development (particularly for adolescent learners) and especially for its positive effects on aspects related to learner affect, such as self-esteem and motivation (Stern, 1980; Crookall, 1984; Smith, 1984; Morgan \& Saxton, 1988; Kitson \& Spiby, 1995; Wagner, 1998; Stinson \& Wall, 2003).

Within all of this recent activity, conventional theatre and its particular process and methods often gets overshadowed, particularly in L2 learning contexts. Part of the reason for this is likely the strong association between conventional theatre and full-scale productions (i.e. with sets, lights, props and costumes); an association that perhaps discourages interested teachers from considering theatrical activity more earnestly. The current exploration, then, presents an accessible compromise: I introduce an activity that is still fundamentally theatrical in nature but abbreviates the rehearsal process into a manageable hour or two of work. In this way, it can be conceptualized as a 'small-scale' form of drama teaching, in the manner discussed in Schewe (2013). Such a 
modified classroom task is, at its core, simply an introduction to scene analysis rather than a full process of rehearsal, but given the many restrictions on time and resources that teachers often face, I feel it works well as a compromise: the central focus is on theatre technique, but students have ample opportunity to explore and practice the language of the scripts as well. At the same time, one could argue that as long as the focus is on employing the results of analysis in a performance, the activity does not constitute an aberrant recontextualisation of the practice. That is to say, while the activity is removed from an actual theatrical process, it retains its intended function and its focus on performative analysis, as opposed to a literary analysis. We are, after all, still asking students to explore separate identities and patterns of discourse by embodying the source text and justifying their performance choices with evidence from that source text. With this in mind, I would reason that so long as the purpose of the activity is to inform performance of a given text, such an employment of theatre practice as a pedagogical instrument does not lessen the activity's transformative potential.

In order to correctly position this performative script analysis activity within the spectrum of existing activities, it is necessary to maintain the distinction, intimated above, between drama in the 'traditional' sense and drama in the 'pedagogical sense'. The former refers to performed narratives, an art form historically associated with the tradition of theatre that emerged in classical Greece (Brocket \& Hildy, 2008). The latter, which can be collectively referred to as 'educational drama' (after the term in Wagner, 1998), is a broad category of similar approaches that prioritise the process of improvisation (within a dramatic context) over rehearsed performance. While it is not necessarily the case that these two distinct approaches to imaginative role-play are in direct opposition in terms of potential content, they are certainly in opposition in terms of the emphasis that educational drama puts on process and traditional drama puts on product. Scripted role-play, of which drama constitutes perhaps the most elaborate example, makes use of a set text, and this text effectively restricts the range of content and language to be covered, and places a greater premium on the performance of that script and the accuracy of the language therein. Thus, while educational drama is typically unconcerned with public presentation, scripted role-play, contrastingly, is concerned with how an audience will ultimately receive a performance (e.g. see Hornbrook, 1998 for a fuller discussion of the distinction between the two).

When one considers the emergence of educational drama in L2 learning contexts, one can get the sense that, for teachers, some of the appeal of (largely) unscripted role-play originates in the relative freedom and agency it affords its participants, in comparison to conventional scripted role-play, and also the fact that it lowers certain stakes for the participants by not requiring them to make a public performance. In terms of this agency, improvised role-plays require that the participants are actively engaged in content creation, otherwise the role-play (i.e. the 'drama' they enact for themselves) loses its vitality and cannot be sustained. In scripted theatre, one could argue that the nature of agency changes as performers are charged with embodying their roles with their own 
personality while at the same time respecting the original author and using the information contained within the play to justify performance choices. This process of looking for information within the script is the key objective of the performative script analysis activity described in this paper.

\section{Script analysis}

The current study looks at a scripted role-play task with a form closely associated with the procedures and purpose it would have as part of a regular theatrical rehearsal. That is to say, within a process that leads to an eventual public performance, various warm-ups, improvisation exercises, drama games, techniques, and other rehearsal methods all serve the greater purpose of motivating and validating the performance choices for each scene. So in this way, the entire purpose of the script analysis task is to prepare for that eventual public performance. Those who are interested in learning more about the functionality of various rehearsal and actor training activity are encouraged to read further; as an example, in course books written specifically for high school drama courses (e.g., Mackey \& Cooper, 2000; Baines \& O'Brien, 2006; or Millard \& Richardson, 2006). For the current study, it will suffice to say that the basic technique of script analysis (and reanalysis) described below emulates, in an abbreviated format, a typical process from a conventional rehearsal.

Script analysis is a fundamental part of performance preparation in theatre (and one would imagine this holds true for similar media as well, such as cinema, television, etc.). In its simplest form, it is a process by which actors and production staff (typically the director), both individually and collaboratively, work their way through a script to understand the story and themes of the play, to develop a strong sense of the characters and their respective motivations within the story, and to establish the nature of their particular character's relationships with other characters. To be certain, not all historical periods of theatre required such in-depth analysis, and many playwrights of previous eras often expressed thoughts, emotions, and motivations quite directly to the audience (Shakespeare certainly comes to mind here). So, to be accurate, the process of script analysis being described in this paper aligns more closely with contemporary (i.e. 20th and 21st century) theatrical practice (e.g., Perry, 2001) and, as it is an integral part of modern theatre training, it should be familiar to anyone who has taken acting classes anytime within recent decades. That being said, the scripts that were used in this exploratory study did not actually come from the theatre world, but from American television programs.

With the last point above, and in the interest of transparency, I will admit that my activity is not intended exclusively for the analysis of theatre plays. However, with that being stated, the scripts used in my activities were rehearsed and ultimately performed live before an audience (albeit a small one), so they became, in essence, theatrical performances rather than performances recorded on visual media. This decision to use these works from outside of theatre actually affords teachers access to a much greater variety of ostensibly authentic 
target language as it widens the range of available texts to include television and film. Both of these genres of scripted role-play can be reinterpreted for the mode of theatre, allowing analysis of a given screenplay, for example, to maintain performative emphasis when recontextualised for a live exhibition.

There are two basic approaches to this script analysis activity, and which of the two the students attempt must be decided from the outset as this affects the materials that are required. For the sake of simplicity, I will call these two variations the 'one-text' and 'multi-text' versions. In my current exploration of this activity, as well as in my prior teaching workshop in 2013 and the original attempt of this task with EAP students in late 2011, my students did the 'multi-text' version. Therefore, I will describe it first.

\section{Script analysis with multiple texts (scenes)}

As I have designed it, there are nine required steps and one optional step to this activity. A list of these steps is provided below and is followed by a detailed explanation of each step.
I. Text selection
II. Cold reading
III. Comprehension check (gap noticing)
IV. Look for clues
V. Full read-thru
VI. Pair-up the scenes
VII. Second rehearsal and read-thru
VIII. Performances
IX. The 'reveal' (optional)
$\mathrm{X}$. Consolidation

Step I: Text selection - As the initial text selection and preparation of materials for this activity is crucial to its success, in my opinion, I will discuss this first step in some detail. For my own exploration of this activity, I chose material that I felt was suitable to the level of my participants with situations that were relatively free of abstract concepts, and in doing so I was not targeting any specific theme or linguistic forms. That concession aside, the target material one selects will naturally depend on the course it is implemented into and it should match with student level and present desired content (themes, linguistic forms, sociocultural features, etc.). The teacher needs to select a story in which the same two (or three) characters appear together in multiple scenes. There should be at least two different scenes and, ideally, the scenes would represent contrasting portions of an overall storyline. For example, a teacher could select David Mamet's Olleana and use an excerpt from the first act and one from the third act (as I did previously for a seminar on this topic), as there is a clear shift in the relationship dynamic of the characters between those two acts. It is important that the characters are the same in each scene. In practice, this can be 
difficult and I will admit that usually one will have to invest a substantial block of time to find suitable scripts. However, I do feel the ability to compare the same characters and how they interact in different scenes is an essential part of this activity. Therefore, if finding a play proves difficult, as I suggested above, teachers should consider using television programs or film script, as I did in the current study, if level-appropriate source material with contrasting scenes is not forthcoming. One additional reason for this suggestion should be obvious enough. For example, television comedies, and especially 'sitcoms', are episodic and character driven and typically tend to take place in a limited number of recurring locations. They usually feature many short scenes with the same characters, and these characters often have individual traits and relationships that are well-enough expressed in the language of the script. I find this makes them especially suitable for use in this activity, although teachers should take care and gauge whether or not they think that their students would understand the humour of each situation (although it is not strictly necessary that they find the scenes funny, of course).

Once a pair of scenes has been found, both texts should be reformatted to remove any use of the characters' names. These names should be replaced by simple pseudonyms, ones that are preferably gender neutral, such as 'A', and 'B'. To explain, while pseudonyms such as 'Man', 'Woman', 'Man 1', 'Man 2', and so on, would conceivably be fine to use, for my implementation of this activity, I never specify the sex of a character as this is the kind of additional information that I want the students to consider and look for when analysing their scripts.

I recommend that any stage directions which explicitly denote the location of the scene or some aspect of the characters' identities be removed as well. Simple directions such as 'laughs', 'looks down', or 'exits the room' can be left in the script so long as information about the character or location is not explicitly mentioned in those directions. All together, this process of paring down a script results in what is referred to as an 'open scene' in theatre. While certainly a number of interpretations are possible with a text as written, removing the names and directions encourages further exploration and multiple interpretations of the same scene by focusing attention solely on what information is provided in the dialogue.

Step II: Cold reading - With the scripts selected and prepared for use, the activity can commence. Each group of students is given one of the two prepared scenes (face down). Students should be arranged so that there is enough space between groups and, ideally, that groups working on the same scene are not seated directly next to each other. When prompted, each group turns over their scenes and begins reading it aloud with no preparation time. I typically treat this first attempt as a literal 'cold reading', meaning that the students work through the text without any warm-up with it at all, hence they are 'cold'. The time allotted for this will depend on the length of the text, but I aimed for ten minutes as the scenes I selected both times were longer in length due to my students slightly advanced proficiency. 
Step III: Comprehension check (gap noticing) - Once the cold reading has finished, students spend a short portion of time going through the script together and resolving any comprehension problems they have. This is a move to push for deliberate awareness of language gaps encountered during the cold reading. If necessary, certain items can be discussed at the class level to promote awareness, otherwise this work is merely monitored by the teacher for the time being. Students have five minutes for this step.

Step IV: Look for clues - Once the language focus concludes, the next step is for each student to figure out what kind of person his or her character is by looking for 'clues' within the scene. In this case, these clues are not deliberately composed by the author to function as a puzzle. Rather, as an author writes a scene, certain features and aspects of each character will affect the way they communicate, including the type of language they use and do not use. In other words, students should look for any indicators of gender, occupation, status (or social class), and so on. Additionally, they should use the text to help deduce other details, such as where the scene takes place and what the characters are doing. Usually a scene will have just enough of this information expressed in language for the students to be able to make informed guesses. Students are given ten minutes to work through the script in this manner. At this stage, the teacher has the option, which I recommend, to discuss with the whole class what the students have discovered about their characters within their individual groups. This gives everyone a chance to share what they have understood about the scenes so far. I would allocate a further five minutes or so for this additional option.

Step V: Full read-thru - Once the clues have been found and discussed, the next step is for the groups to attempt the same scene again with the new understanding of their characters and the situation that they gained through looking for clues. They have ten minutes to further discuss possible performance choices and try their scenes again. Memorisation is not required, so students may freely consult their scripts. They are invited to parse their lines so that may glance down to remember a chunk of text but otherwise concentrate more on interaction with their partner(s) when they speak their lines. During this stage, teachers should monitor the rehearsals to ensure that students are, at the very least, starting to consider contextual aspects of the story in their rehearsals.

Step VI: Pair-up the scenes - After the full read-thru, each group is paired with a group that holds the alternate scene to their own. While the characters are the same in both scenes, this is not confirmed for the students until this point in the process. While it is not essential that this information be kept secret from the students during the first five steps, I have found that the delayed reveal does make students that much more curious about the content. Within each pairing of groups, students take turns performing their scenes for each other and then 
discuss their opinions about their characters. During this discussion, the teacher should help guide them to consolidating the information in both scenes to help students arrive at a more 'definitive' set of performance choices for each scene. Therefore, certain assumptions about characters and their relationships, not to mention how they behave in a certain situation, should be compared with how these characters interact in a different context within the story. This discussion should help students decide if certain performance choices are valid for both their scene and for their characters given this new information. Under normal conditions, this step takes about ten to fifteen minutes depending on the length of the scenes.

Step VII: Second rehearsal and read-thru - After the prior discussion with their complementary groups, students should focus on their original scenes once again and use the information they have acquired up until this point to inform their performance choices and then they should read-thru their original scenes again. If they have time to do more than one read-thru during this step, I would recommend that they be encouraged to consider physical aspects of the scene (in other words, the 'blocking', or pattern of movement, within the scene) if such encouragement has not already been given. Considering what characters are physically doing, and deciding their proximity to each other, can help further "flesh out" how the language of the scene can be performed. This step should take about five to ten minutes, depending on script length.

Step VIII: Performances - Although the script will be familiar to the students by this point, each group will still have their own interpretations of their scenes. Therefore, sharing performances of each scene is a good way to further stimulate discussion of the scenes, the characters, and the story in general. So, as a penultimate mandatory step, students should perform their scenes for each other and then discuss their impressions of the activity and the reasons behind some of their performance choices. The duration of this step will depend on the number of groups performing.

Step IX: The 'reveal' (optional) - This optional step is only available if a recorded performance of the selected script already exists. After the students have presented their own versions of both scenes, they watch an 'actual' performance of the script (which in the case of a television show would be a video of the particular episode from which the script was taken). If this is done, it should be of some interest to the students as they can see to what extent their interpretations match those of professional actors. I would show such a performance not to establish an exemplar or rubric to assess desired pedagogical outcomes, but merely to show an assumedly well-rehearsed and authentic interpretation by native speakers (or non-natives speakers with native-like proficiency). A general discussion of the scenes, and of the activity itself, can follow this. 
Step X: Consolidation - At the conclusion of the performances, and the optional 'reveal', the final step in the process is, of course, for the teacher to lead a discussion that focuses on language use within the activity. The content that gets covered here will depend on the performances, of course, but many teachers will likely want to devote some time at this final stage to demonstrating and discussing prosody- particularly in regards to sentence stress and how this can change the meaning of the utterance. If a teacher has selected a text in order to introduce or consolidate a grammar point or vocabulary set, this final step would naturally be an appropriate time to discuss those features, although such discussion can, of course, occur earlier if the teacher wants students to utilise this information during rehearsal. Although time pressures can often truncate or completely omit such a final step, I recommend at least ten minutes for this important discussion and language focus.

\subsection{Variation with a single text (scene)}

If just a single scene is to be used, the only change to the above procedures is in step VI. Instead of sharing two complementary scenes, two groups share their interpretations of the same scene and then discuss that scene together. Otherwise, the activity proceeds in exactly the same fashion.

One easy alternative procedure that comes to mind is to simply split the single scene in half. This is feasible so long as each half of the scene provides enough material (language and explanatory content) to work with, that is to say, the given situation and the relationship between the characters involved can be adequately understood even when split in half. What constitutes 'enough' and 'adequately' in this case will naturally depend on the individual learning context, but for my university student participants a one to two minute scene generally provided sufficient content for group discussion and performative analysis, so I imagine this figure could be offered as a baseline to follow when looking at potential single texts to split.

I had elected to design this activity originally with multiple scenes (involving the same characters) because that arrangement allows groups to work on different texts, which brings more input into the lesson. Moreover, the possible differences in context and character behaviour between different scenes makes an excellent prompt for discussion. However, even with these reasons being stated, if only one script (scene) is used, and regardless of whether or not it is split in half as well, the activity should still progress in much the same way.

\section{Student Feedback}

The four participants in this current initial exploration (and two additional participants who opted out of data collection) completed two 120 minute sessions. We met once a week for two weeks. For each session, a different source was used to obtain multiple scenes. Both sources were transcripts I made of scenes from popular American television sitcoms. For both days, we followed 
the same procedures for the script analysis task as described in the previous section. At the conclusion of three hours of activity (two full iterations of the task), everyone was given the three questions as a short take-home, post-task survey and emailed their answers to me within 24 hours. The students provided answers in English and each student was given a pseudonym for the purposes of analysis.

The following three questions were included on the survey:

- How difficult did you find the two activities?

- What did you like about the activities?

- What can you say about your language learning in regards to doing these activities?

An analysis of the responses shed some light on the potential of this activity for language practice. Firstly, in regards to the difficulty of doing script analysis (question one), all four participants (as I expected) encountered unfamiliar vocabulary and expressions. In addition to this, Judy noted,

... understanding the context and people's emotion [was hard] ... [ ]... and [it was] difficult to express a character's feeling. (Judy, task survey)

Another student, Lucy, was alone in discussing rehearsals themselves as difficult. She reported,

It is difficult for me to act it, because sometimes I feel embarrassed, especially when I make mistakes. (Lucy, task survey)

None of this is particularly surprising or outside of my expectations as most students would be encountering the scenes for the first time and, moreover, there was little expectation that any of them had substantial experience with acting. Thus, they have to contend with the situation of the scene, the new language therein, and the process of rehearsal all at the same time. Additionally, as all of them were inexperienced performers, it is to be expected that they would need some time to calm their nerves and become comfortable working with others on such an activity.

I used a television sitcom script for both sessions as I presumed that the language and situations were easier to understand than other options that I had found from contemporary theatre. I can concede that this was as much a consequence of a lack in quantity of available material that I had at hand as it was of any other constraint on the activity. Nevertheless, as an initial exploration of this task, I had wanted to make sure that the material being used was easy enough for my students to comprehend so that they could concentrate on the performative aspect of the task more from the beginning, rather than being overwhelmed at the onset by too much unfamiliar language. As a result, I deemed that the sitcom scripts suited the given teaching context well. In spite of 
this decision, one of the students, Susan, admitted afterwards that she had not watched very many English language comedies before and, consequently, she sometimes found the lines difficult to say or difficult to imagine their meaning. This helps to remind us that humour may, in some cases, be harder for certain students to comprehend, certainly when cultural differences are taken into consideration.

Despite the difficulties they encountered, all four participants reacted very positively to the script analysis activities. Both Betty and Lucy enjoyed the fact that they could improve their language skills while working on something they found really fun to do. Judy enjoyed the opportunity to learn more about other cultures by assuming a new identity in the drama. Susan liked the moments she truly learned something the most, as she noted in her feedback, writing,

I like to understand gradually. At first, I didn't understand what's happen[ing] [in] the script but through practice and discussing with friends, I can understand what's happen[ing]. That was [my] most favourite moment. (Susan, task survey)

Susan's reflection is valuable as it reminds us of the recursive quality of rehearsal. As she suggested, when actors rehearse a given scene, each execution of that scene builds upon the previous ones, allowing for more and more aspects of the scene, and importantly the language in the scene, to be revealed, considered, or further substantiated. For her, she was slowly able to fully understand the underlying structure and situation after rehearsing the scene with the other participants. I personally find her remarks here to be a simple but compelling example of the kind of experience anyone can have when they actually act out a text and give life to its language.

Practicing this process can also assist with relevant language skills development. Both Betty and Lucy mentioned pronunciation specifically as the area they could improve the most, and Lucy goes so far as to mention that this development makes her more confident to speak with native-speakers. This points to a potential value of theatre in its ability to afford students a 'risk-free' opportunity to imitate or approximate native-like speech using the ostensibly authentic language found in theatre, film and television scripts. Rather than just pronunciation, Susan felt that each script also exposed her to knew language that she could learn. Finally, Judy recognised the potential benefit of learning the type of English featured in the scripts, but she did wonder how much such study could help with academic English.

\section{Conclusion}

The short duration of the activity undertaken in the current exploration, and the experimental nature of this research, did impose certain limitations on analysis. The small number of participants and the minimal scope of my research design are the most obvious limitations, but the lack of a 'true' final public performance to a larger class was also notably absent from the task procedures of this 
particular undertaking. To explain, there were never more than two groups participating, so, in truth, the closest thing to an actual performance for an audience was the final read thru of both scenes - but that was for my benefit alone. Thus, the participants were not able to watch the performances of other paired-up groups and see how those groups interpreted both the scenes and the characters featured within. Furthermore, the relatively advanced level of the participants (corresponding roughly to a B2 or C1 level on the CEFR), and their status as self-selected participants, may have rendered this initial exploration as more of an ideal undertaking of the activity rather than a more realistic or typical undertaking.

With the above limitations acknowledged, this activity does show potential for facilitating language development, certainly in relation to the speaking practice that recursive analytical rehearsal makes possible. As the earlier survey of literature indicated, it is well-established that drama exerts a strong and positive influence on various aspects of learner affect, especially the intrinsic value participants find in doing performance-based activities, even if they initially (and sometimes consistently) find the work to be challenging or embarrassing. The student feedback in the current exploration only further supports this claim and to a certain extent, this enjoyability continues to be the strongest appeal for using theatre and drama in L2 classrooms. From work on the current exploration and its antecedents in earlier classrooms of mine, I would like to offer my opinion that adding a stronger element of analysis into the proceedings, as I have done with the performative script analysis task here, creates additional learning opportunities by necessitating a recursive process of working with the text to discover more and more details. One of the participants in particular, Susan, found the script analysis work enjoyable specifically because she was able to slowly understand more and more about the scenes by rehearsing them a number of times with her classmates. I think that her experience can serve as a suitable exemplar of the type of learning experience that students can expect from such a task.

\section{Bibliography}

Baines, Richard \& O’Brien, Mike (2006): Navigating Senior Drama. Cambridge: Cambridge University Press

Belliveau, George \& Kim, Won (2013): Drama in L2 Learning: A research synthesis. In: Scenario 2, 6-26

Brockett, Oscar G. \& Hildy, Franklin J. (2008): History of the Theatre, 10th Edition. Harlow: Pearson Education Limited

Crookall, David (1984): The use of non-ELT simulations. In: English Language Teaching Journal 38/4, 262-273

Di Pietro, Robert (1987): Strategic Interactions: Learning Languages Through Scenarios. Cambridge: Cambridge University Press 
Donnery, Eucharia (2009): Testing the Waters: Drama in the Japanese University EFL Classroom. In: Scenario 1, 17-35

Hornbrook, David (ed.) (1998): On the Subject of Drama. London: Routledge

Jones, Ken (1982): Simulations in Language Teaching. Cambridge: Cambridge University Press

Kao, Shin-Mei, \& O'Neill, Cecily (1998): Words in Worlds: learning a second language through process drama. Stamford, CT: Ablex Publishing Corporation

Kitson, Neil \& Spiby, Ian (1995): Primary Drama Handbook. London: The Questions Publishing Company

Mackey, Sally \& Cooper, Simon (2000): Drama and Theatre Studies. Cheltenham: Stanley Thornes Ltd.

Mages, Wendy (2008) Does creative drama promote language development in early childhood? A review of methods and measures employed in empirical research. In: Review of Education Research 78/1, 124-152

Maley, Alan \& Duff, Alan (1978): Drama Techniques in Language Learning. Cambridge: Cambridge University Press

Millard, Annie \& Richardson, Catherine (2006): Year 11 Drama Study Guide: NCEA Level One. Auckland: ESA Publications (NZ) Ltd.

Morgan, Norah \& Saxton, Juliana (1988): Teaching Drama: A mind of many wonders. Cheltenham: Stanley Thornes (Publishers) Ltd.

Perry, John (2001): The Rehearsal Handbook for Actors and Directors: A Practical Guide. Marlborough, Wiltshire: The Crowood Press

Piazzoli, Erika (2011): Process Drama: the use of affective space to reduce language anxiety in the additional language learning classroom. In: Research in Drama Education 16/4, 557-573

Piazzoli, Erika (2010): Process drama and intercultural language learning: an experience of contemporary Italy. In: Research in Drama Education 15/3, 385-402

Podlozny, Ann (2000): Strengthening Verbal Skills Through the Use of Classroom Drama: A Clear Link. In: Journal of Aesthetic Education 34/3-4, 239-276

Schewe, Manfred (2013): Taking Stock and Looking Ahead: Drama Pedagogy as a Gateway to a Performative Teaching and Learning Culture. In: Scenario $1,5-27$

Smith, Stephen M. (1984): The theatre arts and the teaching of second languages. Reading, MA: Addison-Wesley Publishing Company, Inc.

Stern, Susan (1980): Why drama works: a psycholinguistic perspective. In: Oller, John W. \& Richard-Amato, Patricia A. (eds.): Methods That Work: A Smorgasbord of Ideas for Language Teachers . Rowley, MA: Newbury House Publishers, Inc., 207-225 
Stinson, Madonna \& Wall, Debbie (2003): Dramactive (Book One). New South Wales: McGraw-Hill Australia

Stinson, Madonna \& Winston, Joe (2011): Drama education and second language learning: a growing field of practice and research. In: Research in Drama Education 16/4, 479-488.

Wagner, Betty (1998): Educational Drama and Language Arts: What Research Shows. Portsmouth, NH: Heinemann

Wessels, Charlyn (1987): Drama. Oxford: Oxford University Press 